Barbosa, I.G. 117

Bauer, M.E. 145

Beurel, E. 140

Bonsi, R. 79

Brietzke, E. 131

Capuron, L. 95

Cerejeira, J. 72

Cirillo, C. 88

Fontenelle, L.F. 152

Galimberti, D. 79

Grassi-Oliveira, R. 145

Hartmann do Prado, C. 145

Adiposity 95

Alzheimer's disease 79

Anti-basal ganglia antibodies 152

Aspirin 117

Behavioral comorbidities 95

Biomarker 102

Cognition 88

Cortisol 145

Cytokines 79, 95, 102, 131, 145

Delirium 72

Depression 88, 117, 131, 140

Fatigue 95

Glycogen synthase kinase-3 140
Lagarto, L. 72

Lasselin, J. 95

Machado-Vieira, R. 117

Maes, M. 131

Mansur, R.B. 131

Marques, A.H. 152

McIntyre, R.S. 131

Miguel, E.C. 152

Mondelli, V. 102

Mukaetova-Ladinska, E.B. 72

Müller, N. 71, 109, 123

Noto, C. 131

Pessoa Rocha, N. 88
Reis, H.J. 88

Rizzo, L.B. 131

Rodrigues, D.H. 152

Scarpini, E. 79

Serpente, M. 79

Soares, J.C. 117

Teixeira, A.L. 71, 117, 145, 152

Vanden Berghe, P. 88

Wieck, A. 145

Zajkowska, Z. 102

\title{
Subject Index Vol. 21, No. 2-3, 2014
}

Hypocortisolism 145

Immune response 72

- system 79, 88

Immunization 79

Inflammation $72,79,88,95,102,109$,

$123,131,140,145$

Inflammatory marker 102

Interleukin 117

Lymphocytes 117, 145

Major depression 123

Mania 117

Metabolic disorders 95

Microglia 79

Mood and cognitive symptoms 95

- disorder 117
Obesity 95

Obsessive-compulsive disorder 152

Parkinson's disease 88

Post-traumatic stress disorder 145

Proinflammatory cytokines 140

Psychoneuroimmunology 109, 123

Psychosis 102

Rheumatic chorea 152

Schizophrenia 102, 109

Vaccination 79 